\title{
Identification of distinct polarized macrophage subsets in inflammatory arthritis
}

\author{
C Ambarus $^{1 *}$, S Krausz 1 , J Hamann², M H Wenink ${ }^{3}$ TRD J Radstake ${ }^{3}$, P P Tak ${ }^{1}$, D Baeten ${ }^{1}$ \\ From 5th European Workshop on Immune-Mediated Inflammatory Diseases \\ Sitges-Barcelona, Spain. 1-3 December 2010
}

The concept of macrophage polarization describes the heterogeneity of activated macrophages under specific microenvironmental conditions. Based on their pro- or anti-inflammatory functions, M1 and M2 macrophages have been described. We aim to assess type 2 inflammation in spondyloarthritis (SpA) versus type 1 inflammation in rheumatoid arthritis (RA). Here, we investigated the expression of cell surface molecules on in vitro differentiated human macrophages.

Monocytes were isolated from peripheral blood of healthy donors and patients with SpA and RA and differentiated for 4 days in the presence of IFN- $\gamma$, IL-4 or IL-10. Expression of various surface markers was analyzed by flow cytometry and confirmed by RT-PCR.

We first confirmed that IFN- $\gamma$ (classical activation), IL-4 (wound healing) and IL-10 (immunoregulation) lead to functionally distinct macrophages by stimulation with TLR agonists and subsequently measuring their cytokine production. In the next step we identified reliable phenotypic markers for each macrophage subset. IFN- $\gamma$ induced selective up-regulation of CD64 and CD80, IL-4 strongly up-regulated CD200R, whereas IL-10 up-regulated CD163 and CD16. We next polarized monocytes from patients and healthy donors and found that marker expression was similar in all groups. We also assessed the phenotype of circulating monocytes and found that CD64 was higher, while CD16 was lower expressed on SpA versus healthy donor monocytes.

Finally, we performed a similar analysis on SpA synovial fluid macrophages and preliminary data indicate that distinct populations are present in inflamed synovium.

In conclusion we identified specific phenotypic markers for functionally distinct human macrophage subsets. Analysis of peripheral blood monocytes indicates

${ }^{1}$ Dept. of Clinical Immunology and Rheumatology, Academic Medical Center/ University of Amsterdam, The Netherlands

Full list of author information is available at the end of the article that there is no intrinsic defect in their polarization potential in SpA and RA. However, M1 marker CD64 was higher, while M2 marker CD16 was lower expressed by SpA versus healthy donor monocytes. Current analysis of synovial macrophages will delineate the exact polarization status in the inflamed joint.

\section{Author details}

${ }^{1}$ Dept. of Clinical Immunology and Rheumatology, Academic Medical Center/ University of Amsterdam, The Netherlands. ²Dept. of Experimental Immunology, Academic Medical Center/ University of Amsterdam, The Netherlands. ${ }^{3}$ Dept. of Rheumatology, Radboud University Medical Center Nijmegen, The Netherlands.

Published: 25 November 2010

doi:10.1186/1479-5876-8-S1-P39

Cite this article as: Ambarus et al:: Identification of distinct polarized macrophage subsets in inflammatory arthritis. Journal of Translational Medicine 2010 8(Suppl 1):P39.

Submit your next manuscript to BioMed Central and take full advantage of:

- Convenient online submission

- Thorough peer review

- No space constraints or color figure charges

- Immediate publication on acceptance

- Inclusion in PubMed, CAS, Scopus and Google Scholar

- Research which is freely available for redistribution 